\title{
Effects of Surfactants on the Oxidation of Aromatic Azo Dyes
}

\author{
AMITA V. TANDEL ${ }^{1}$ and HIMANSHU D. PATEL ${ }^{2}$ \\ ${ }^{1}$ Mahatma Gandhi Institute of Technical Education \& Research Centre, \\ Navsari, Gujarat-396450, India \\ ${ }^{2}$ Dr. APJ Abdul Kalam Govt. College, Silvassa-Dokmardi, DNH-396230, India \\ dr.amitapatel26@yahoo.com
}

Received 24 November 2015 / Accepted 18 December 2015

\begin{abstract}
The oxidation of methyl red (MR) and methyl orange (MO) by Vanadium (V) in aqueous sulphuric acid media in the presence of anionic surfactants at different temperatures has been investigated. The reaction studied spectrophotometrically in aqueous sulphuric acid medium is first order in vanadium (V) methyl red (MR) and methyl orange (MO). Plots of $\mathrm{k}_{\mathrm{obs}}$ versus $\left[\mathrm{H}^{+}\right]$are linear with positive intercepts on $\mathrm{k}_{\mathrm{obs}}$ axes, suggesting the formation of a complex between vanadium (V) and dye. The activation and thermodynamic parameters have been calculated. The kinetic model use in this study to describe the dependence of rate constant on the reaction mechanism proposed.
\end{abstract}

Keywords: Oxidation, Kinetics, Mechanism, Activation and thermodynamic parameters

\section{Introduction}

Though kinetics of oxidation of a number of organic compounds by vanadium $(\mathrm{V})$ has been reported, kinetic study of oxidation of aromatic compounds by $\mathrm{V}(\mathrm{V})$ has not been made so far. A detailed kinetic study of oxidation of methyl red (MR) and methyl orange (MO) in aqueous sulphuric acid media in presence of vanadium $(\mathrm{V})$ has been carried out. The influence of the added anionic surfactants on the reaction has also been investigated. The results enable us to understand the nature of the species involved in the reaction and their relative reactivities. Micellar systems well suited for various separation and catalytic process $^{1-3}$. It is reported that micelles have effects on the rate of reactions ${ }^{4-9}$. The kinetic model use in this study to describe the dependence of rate constant on the reaction mechanism proposed by Bruice et al., ${ }^{10}$ and applied by Piszkiewicz ${ }^{11}$.

\section{Experimental}

All chemicals used were of AR grade. Ammonium metavanadate (prepared in $2 \mathrm{M} \mathrm{H}_{2} \mathrm{SO}_{4}$ ) and methyl red (MR) and methyl orange (MO) solutions were prepared and standardized 
according to the method of Gopala Rao et al. ${ }^{12,13}$. The dye solutions were always prepared fresh. Surfactants solutions were prepared in double distilled water. Purities of all the chemicals were checked before the use.

\section{Rate measurement}

The course of the reaction was followed by measuring the optical density of the unreacted dye with a Shimadzu (UV-2450) UV-Visible double beam spectrophotometer at $421 \lambda_{\max }$ and $468 \lambda_{\max }$ for methyl red and methyl orange respectively. Under these conditions Beer's law was obeyed by the dye which has absorption maxima in this range.

\section{Stoichiometry}

The stoichiometry of the reaction was determined by mixing indigo carmine in micellar environment with anionic surfactant, in $0.5 \mathrm{M} \mathrm{H}_{2} \mathrm{SO}_{4}$ with known excess of $\mathrm{V}(\mathrm{V})$, after the completion of the reaction which is indicated by the discharge of the blue colour of the dye was found to consume four moles of $\mathrm{V}(\mathrm{V})$. The formation of free radicals during the reaction was confirmed by the induced polymerization of acrylonitrile, whereas neither $\mathrm{V}(\mathrm{V})$ nor dye solution alone induced polymerization.

\section{Results and Discussion}

The reaction is found to be pseudo first order in the absence of surfactant at different temperatures as evidenced by the plot of $\log \left(\mathrm{A}_{\mathrm{t}}-\mathrm{A}_{\infty}\right)$ versus time, which was linear under the condition $[\mathrm{V}(\mathrm{V})]>>[\mathrm{Dye}]$ indicating the order in the methyl red (MR) and methyl orange (MO) to be unity (Figure 1). The figures show the effect of temperature in the absence of surfactants, an increase in temperature tended to pronouncedly increase in the oxidation of both the dyes. The observed pseudo first order rate constants $\left(\mathrm{k}_{\mathrm{obs}}\right)$ were calculated from these plots which increase with increase in the temperature. The plot of pseudo first order rate constants $\left(\mathrm{k}_{\mathrm{obs}}\right)$ versus $\mathrm{V}(\mathrm{V})$ concentrations is found to be linear and passing through the origin indicating the reaction is first order (Figure 2). The rate constants determined at different $\mathrm{V}(\mathrm{V})$ concentration is found to increase the rate of reaction.

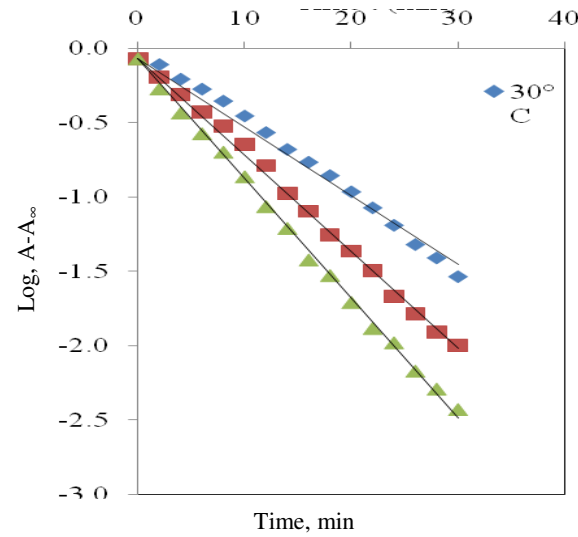

Figure 1. Plot of versus time $\mathrm{t}(\mathrm{min})$ for the oxidation of methyl red in absence of surfactant at different temperatures [Methyl red] $=4.0 \times 10^{-5}$ $\mathrm{M},[\mathrm{V}(\mathrm{V})]=1 \times 10^{-3} \mathrm{M},\left[\mathrm{H}^{+}\right]=0.5 \mathrm{M}$

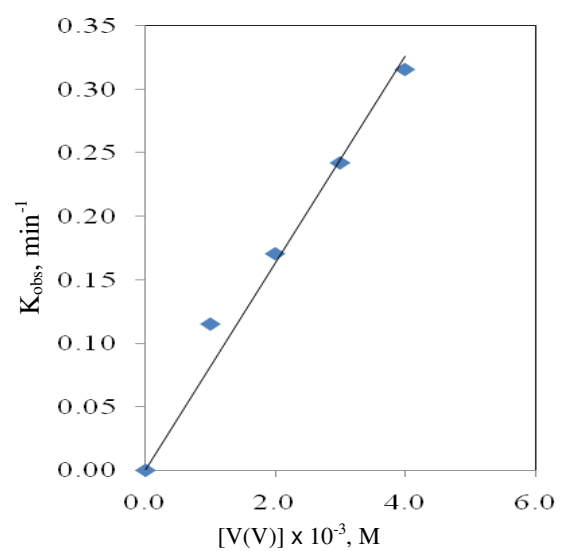

Figure 2. Pseudo first-order rate constants for the oxidation of methyl red in aqueous phase at different concentration of $\mathrm{V}(\mathrm{V})$ at $30{ }^{\circ} \mathrm{C}$ temperature. [Methyl red] $=4.0 \times 10^{-5}$ $\mathrm{M},\left[\mathrm{H}^{+}\right]=0.5 \mathrm{M}$ 
The plot of logarithms of $-\log \left(\mathrm{A}_{\mathrm{t}}-\mathrm{A}_{\infty}\right)$ versus time, $\mathrm{t}(\mathrm{min})$ is linear under the fixed concentration of $\mathrm{MR}$ and $\mathrm{MO}$, fixed concentration of $\mathrm{V}(\mathrm{V})$ ion and varying the concentration of $\left[\mathrm{H}^{+}\right]$at $30^{\circ} \mathrm{C}$. The plot of rate constants $\left(\mathrm{k}_{\mathrm{obs}}\right)$ versus $\left[\mathrm{H}^{+}\right]$concentrations are found to be linear (Figure 3). The acceleration of the reaction with increase in $\left[\mathrm{H}^{+}\right]$in the case of many $\mathrm{V}(\mathrm{V})$ oxidations has been explained by Waters et al., as due to the formulation of the active species $\left[\mathrm{V}(\mathrm{OH})_{3}\right]^{+2}$ species which depends on the acid types and their concentration range. It has been established by research workers that in aqueous sulphuric media $\left(\leq 4.5\right.$ mol. $\left.\mathrm{dm}^{-3}\right)$, the kinetically active species of $\mathrm{V}(\mathrm{V})$ is $\left[\mathrm{V}(\mathrm{OH})_{3} \mathrm{HSO}_{4}\right]^{+}$and the equilibrium leading to the active species is given by research workers ${ }^{14-18}$. The result can be explained by considering the proposed mechanism (Scheme 1).

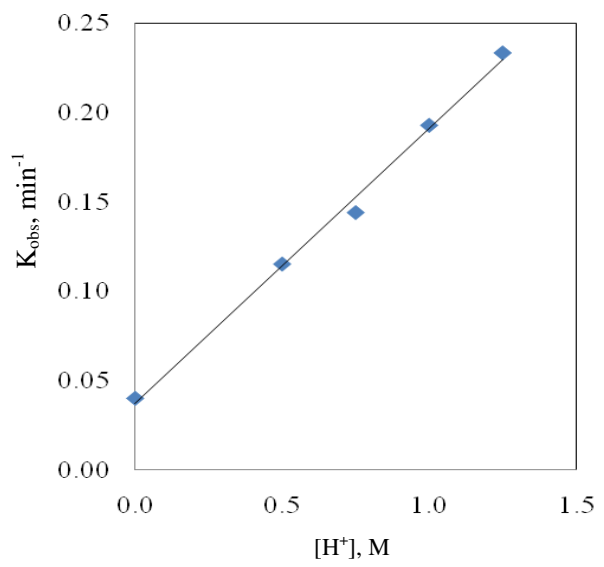

Figure 3. Pseudo first-order rate constants for the oxidation of methyl red in aqueous phase at different concentration of $\left[\mathrm{H}^{+}\right] \mathrm{M}$ at $30{ }^{\circ} \mathrm{C}$ temperature, $\left[\right.$ Methyl red] $=4.0 \times 10^{-5} \mathrm{M}$, $[\mathrm{V}(\mathrm{V})]=1 \times 10^{-3} \mathrm{M}$

$$
\begin{aligned}
& \mathrm{VO}_{2}^{+}+\mathrm{H}_{3} \mathrm{O}^{+}+\mathrm{HSO}_{4}^{-} \rightleftarrows\left[\begin{array}{c}
\mathrm{K}_{1} \\
\mathrm{O}
\end{array}\right]_{\mathrm{O}}^{\mathrm{OH}} \\
& \text { A } \\
& -\mathrm{N}=\mathrm{N}-+\mathrm{A} \stackrel{\mathrm{K}_{2}}{\rightleftarrows}[-\mathrm{N}=\mathrm{N} \stackrel{\mathrm{OH}}{\mathrm{OH}} \underset{\mathrm{OSO}}{-}]^{-} \\
& \text {I.C. } \stackrel{\mathrm{K}_{3}}{\longrightarrow} \underset{\substack{\mathrm{OH} \\
\text { (Free radical) }}}{-\mathrm{N}-\mathrm{NO}}+\mathrm{VO}_{2}^{+2}+\mathrm{H}_{2} \mathrm{O}+\mathrm{H}^{+}+\mathrm{HSO}_{4} \\
& \text { Free radical }+\mathrm{V}(\mathrm{V}) \stackrel{\text { Fast }}{\longrightarrow} \underset{\text { Nitroso Compand }}{2-\mathrm{NO}}+\mathrm{V}(\mathrm{IV})+\mathrm{H}^{+}
\end{aligned}
$$

\section{Scheme 1}


The rate of oxidation of MR and MO by $\mathrm{V}(\mathrm{V})$ depends on the first power of the concentrations of two reactants. Therefore, the rate law for the oxidation of dye can be given by the expression,

$$
-\mathrm{d}[\text { dye }] / \mathrm{dt}=\mathrm{k}^{\prime}[\mathrm{V}(\mathrm{V})][\text { dye }]\left[\mathrm{H}^{+}\right]\left[\mathrm{HSO}_{4}^{-}\right]
$$

Where, $\mathrm{k}^{\prime}$ is the second order rate constant. At constant $\left[\mathrm{H}^{+}\right]$the rate laws equation (1) reduces to

$$
-\mathrm{d}[\mathrm{dye}] / \mathrm{dt}=\mathrm{k}^{\prime}[\mathrm{V}(\mathrm{V})][\text { dye }]
$$

Anionic surfactants (viz., SDS and SDES) micelles affect the pseudo first-order rate constant for the oxidation of MR and MO at different concentrations of anionic surfactants (viz., SDS, SDES $)$ and at different temperatures. The rate constant $\left(\mathrm{k}_{\mathrm{obs}}\right)$ increases with increase in anionic surfactant concentration passes through a maximum and decrease at high surfactant concentration (Figure 4). The increase in rate in the premicellar region of the anionic surfactant may be due to mixed micelle formation of the dye molecule and surfactant molecules, at lower concentration of anionic surfactants (viz., SDS, SDES). Considerable evidence is available to show that concentration of reactants into a small bulk at the micellar surface is major source of enhancement of bimolecular reactions. The rate of the reaction increase in following order:

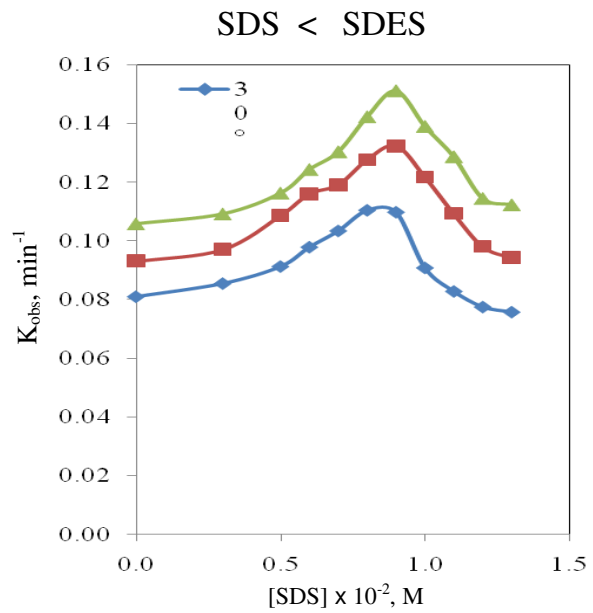

Figure 4. Influence of SDS on oxidation of methyl orange by $\mathrm{V}(\mathrm{V})$ at different temperatures, [Methyl orange $]=4.0 \times 10^{-5} \mathrm{M}[\mathrm{V}(\mathrm{V})]=5 \times 10^{-4} \mathrm{M}\left[\mathrm{H}^{+}\right]=0.5 \mathrm{M}$

It is quite possible that the mixed micelle of dye ion and anionic surfactants (viz., SDS, SDES) are formed and $\mathrm{V}(\mathrm{V})$ is bound in the micelle. The mixed dye and surfactant (viz., SDS, SDES) micelles formed can also affect the proximate approach of $\left[\mathrm{V}(\mathrm{OH})_{3} \mathrm{HSO}_{4}\right]^{+}$by hydrophobic force. Thus with increase in the concentration of anionic surfactants (viz., SDS, SDES) the rate increase and attains a maximum value. With further increase in the concentration of anionic surfactants (SDS, SDES) produces increase in the concentration of counter ions $\mathrm{Na}^{+}$that displaces the $\mathrm{H}^{+}$or $\left[\mathrm{V}(\mathrm{OH})_{3} \mathrm{HSO}_{4}\right]^{+}$ions in the proximity of the bound dye molecules. This could account for descending branch of the experimental curve observed. The reaction takes place in both the micellar and aqueous media.

The effect of varying concentration of $[\mathrm{V}(\mathrm{V})]$ has been studied in presence of \{fixed [SDS] $=0.9 \times 10^{-2} \mathrm{M}$ at fixed $[\mathrm{MR}]=4.0 \times 10^{-5} \mathrm{M}$, at fixed $\left.\left[\mathrm{H}^{+}\right]=0.5 \mathrm{M}\right\},\left\{\right.$ fixed $[\mathrm{SDS}]=0.9 \times 10^{-2} \mathrm{M}$ at fixed $[\mathrm{MO}]=4.0 \times 10^{-5} \mathrm{M}$, at fixed $\left.\left[\mathrm{H}^{+}\right]=0.5 \mathrm{M}\right\}$ concentration at $30^{\circ} \mathrm{C}$. The result shows that overall catalysis factor slowly increases with an increase in concentration of $[\mathrm{V}(\mathrm{V})]$. 
A resemblance between micellar enzymatic reactions may be shown by considering the factor of overall for SDS and SDES micelle catalysed reaction. The plot of logarithms of $\log \left(\mathrm{A}_{\mathrm{t}}-\mathrm{A}_{\infty}\right)$ versus time, $\mathrm{t}(\mathrm{min})$ is linear under the fixed concentration of $\mathrm{V}(\mathrm{V})$ ion and varying the concentration of IC at $30{ }^{\circ} \mathrm{C}$ (Figure 5). Such plots at different initial concentrations of MR and MO were found to be parallel which indicated the reaction of dye with $\mathrm{V}(\mathrm{V})$ in the micellar environment of SDS and SDES follows pseudo first order.

The rate constant of the SDS and SDES catalyzed reaction in presence of added salts viz., $\mathrm{KCl}, \mathrm{NaCl}, \mathrm{KBr}$ and $\mathrm{Na}_{2} \mathrm{SO}_{4}$ has also been studied. Various salts strongly retarded the oxidation of anionic catalysed dyes. It is found that initially rate decreases and become almost constant with increase in the concentration of salts (Figure 6). The order of retardation with respect to anion is as follows:

$$
\mathrm{SO}_{4}^{-2}>\mathrm{Br}^{-}>\mathrm{Cl}^{-}>\text {no salt. }
$$

Hence the observed retardation in the presence of electrolytes may be due to the interaction between anion of the salt with the positively charged species $\left[\mathrm{V}(\mathrm{OH})_{3} \mathrm{HSO}_{4}\right]^{+}$ and a less reactive species may be formed.

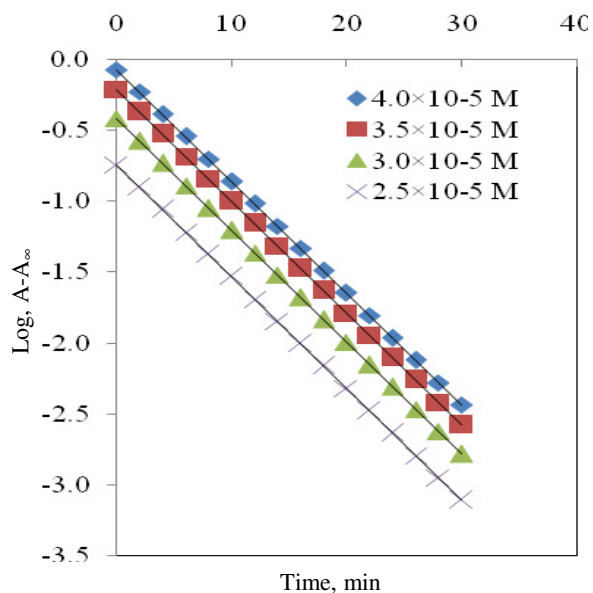

Figure 5. Plot of $\log \left(\mathrm{A}-\mathrm{A}_{\infty}\right)$ versus Time, $\mathrm{t}$ (min) for the oxidation of methyl red under the condition of fixed concentration of $\mathrm{V}(\mathrm{V})$ at $30^{\circ} \mathrm{C}$ in presence of SDES $[\mathrm{V}(\mathrm{V})]$ $=1 \times 10^{-3} \mathrm{M},\left[\mathrm{H}^{+}\right]=0.5 \mathrm{M},[\mathrm{SDES}]=$ $0.39 \times 10^{-3} \mathrm{M}$ \{for Methyl red

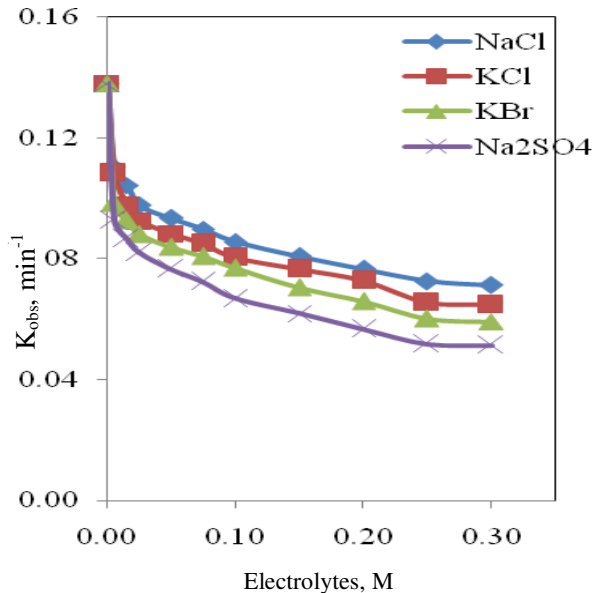

Figure 6. Effect of electrolytes on SDS catalysed oxidation of methyl red and methyl orange by $\mathrm{V}(\mathrm{V})$ at $30^{\circ} \mathrm{C}$, (a) [methyl orange $]=4.0 \times 10^{-5} \mathrm{M},[\mathrm{V}]=0.5 \times 10^{-3} \mathrm{M},[\mathrm{H}]$ $=0.5 \mathrm{M},[\mathrm{SDES}]=0.4 \times 10^{-3} \mathrm{M}$

It may be seen that the addition of acetone and acetic acid with MR and MO to the reaction system reduces the overall catalysis by SDS and SDES (Figure 7). It may be noted that acetone is more effective than acetic acid in reducing the overall catalysis by SDS and SDES.

The effect of temperature on the oxidation reaction of MR and MO with $\mathrm{V}(\mathrm{V})$ ion has been studied at fixed concentrations of surfactant, substrate and $\mathrm{V}(\mathrm{V})$. The reaction is found to obey Arrhenius equation. The plot of $\log \mathrm{k}_{\mathrm{obs}}$ versus $1 / \mathrm{T}$ in absence and presence of surfactants is linear (Figure 8). The values of activation parameters viz., $\mathrm{Ea}^{\#}$, frequency factor $\mathrm{Z}, \Delta \mathrm{S}^{\#}, \Delta \mathrm{H}^{\#}, \Delta \mathrm{G}^{\#}$ are given in Table 1 . The values of activation energies obtained from the slopes of Arrhenius plots for SDS and SDES catalyzed reaction in aqueous solutions suggest that a decrease in activation energy in presence of anionic surfactants (SDS and SDES) relative 
to aqueous medium is one of the factors responsible for the catalysis. Nearly same values of $\Delta \mathrm{G}^{\#}$ in absence and presence of surfactants shows that similar mechanism for oxidation is operative in aqueous and micellar media. The values of $\Delta S^{\#}$ in all systems are negative indicating that the reaction is occurring between ionic species. Micelles do not alter the mechanism of the reaction but only affect the reaction rate.

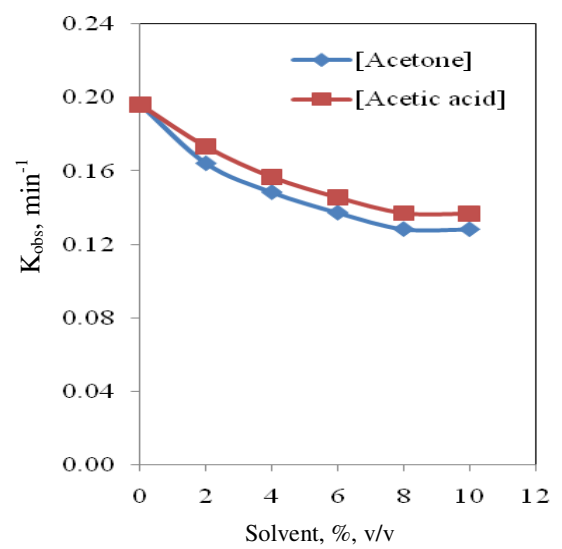

Figure 7. Influence of solvents on oxidation of methyl red and methyl orange by $\mathrm{V}(\mathrm{V})$ at $30^{\circ} \mathrm{C}$. [Methyl red] $=$ $4.0 \times 10^{-5} \mathrm{M},[\mathrm{V}(\mathrm{V})]=1 \times 10^{-3} \mathrm{M},\left[\mathrm{H}^{+}\right]=$ $0.5 \mathrm{M},[\mathrm{SDES}]=0.37 \times 10^{-3} \mathrm{M}$

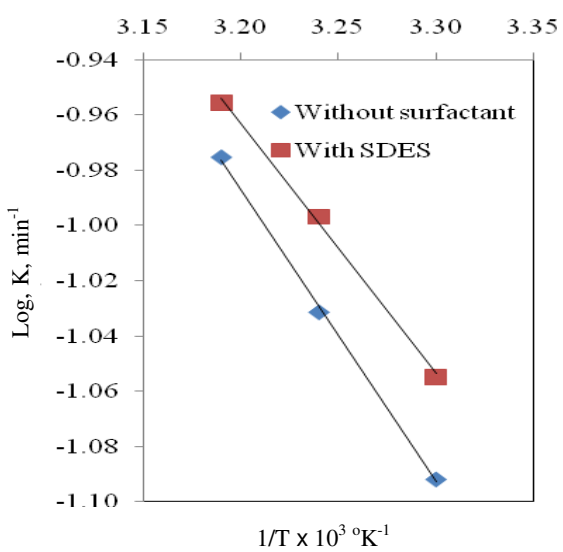

Figure 8. Arrhenius plots for the oxidation of methyl orange by $\mathrm{V}(\mathrm{V})$ in absence and presence of (a) SDES

Table 1. Activation parameters for the oxidation of methyl orange with $V(V)$ in absence and presence of surfactants

\begin{tabular}{cccccc}
\hline Parameters & $\begin{array}{c}\mathrm{E}, \\
\mathrm{kJ} . \mathrm{mol}^{-1}\end{array}$ & $\begin{array}{c}\mathrm{Z}, \\
\mathrm{L} . \mathrm{mol}^{-1} \cdot \mathrm{s}^{-1}\end{array}$ & $\begin{array}{c}\Delta \mathrm{H}, \\
\mathrm{kJ} \cdot \mathrm{mol}^{-1}\end{array}$ & $\begin{array}{c}\Delta \mathrm{S}, \\
\mathrm{JK}^{-1} \cdot \mathrm{mol}^{-1}\end{array}$ & $\begin{array}{c}\Delta \mathrm{G}, \\
\mathrm{kJ}^{-} \mathrm{mol}^{-1}\end{array}$ \\
\hline $\begin{array}{c}\text { In aqueous } \\
\text { solution }\end{array}$ & 20.27 & $2.52 \times 10^{2}$ & 15.24 & -215.74 & 80.60 \\
SDS & 18.55 & $1.34 \times 10^{2}$ & 13.52 & -220.97 & 80.46 \\
SDES & 17.36 & 86.86 & 12.33 & -224.62 & 80.39 \\
\hline
\end{tabular}

Table 2. Values of $n, \log [D]_{50}, 1 / K D$ and $K D$ in oxidation of methyl red by $V(V)$ in presence of anionic and non-ionic surfactants at $30{ }^{\circ} \mathrm{C}$

\begin{tabular}{ccccc}
\hline Surfactants & $\mathrm{n}$ & $\log [\mathrm{D}]_{50}$ & $\mathrm{k}_{\mathrm{D}}$ & $1 / \mathrm{k}_{\mathrm{D}}$ \\
\hline SDS & 3.32 & -2.27 & $2.66 \times 10^{-8}$ & $3.75 \times 10^{7}$ \\
SDES & 2.46 & -3.57 & $1.60 \times 10^{-9}$ & $6.26 \times 10^{8}$ \\
\hline
\end{tabular}

The value of frequency factor in presence and in absence of anionic surfactants shows that the less number of collisions required in forward reaction in the presence of anionic surfactants (viz., SDS \& SDES).

The kinetic results of enhancement of the rate constant by anionic surfactant (SDS, SDES) have been rationalized on the basis of a model proposed by Bruice et al. and applied by Piszkiewicz. A plot of $\log \left(\mathrm{k}_{\mathrm{w}}-\mathrm{k}_{\mathrm{obs}}\right) /\left(\mathrm{k}_{\mathrm{obs}}-\mathrm{k}_{\mathrm{m}}\right)$ versus $\log \left[\mathrm{C}_{\mathrm{D}}\right]$ is found linear with a slope $(\mathrm{n})$ called the index of co-operativity (Figure 9 ). Values of $\log [\mathrm{D}]_{50}$ represent the concentration of detergent required for half maximal catalysis of reaction (Table 2). This demonstrates the existence of function sub-micellar aggregates involving detergent and substrate molecules 
of varying stoichiometries. The value of $n>1$ indicates positive co-operativity, which implies the stimulation of additional molecule by interaction of the first molecule with the micelle. The values of binding constants $\left(\mathrm{K}_{\mathrm{b}}\right.$ which is reciprocal of $\left.\mathrm{K}_{\mathrm{D}}\right)$ are lesser for anionic surfactants. In presence of SDS and SDES, catalysed effect is observed due to approachability $\left[\mathrm{V}(\mathrm{OH})_{3}(\mathrm{HSO})_{4}\right]^{+}$to the strongly bound substrate in the catalytic aggregate of opposite charge and due to the stabilization of ground state of dyes.

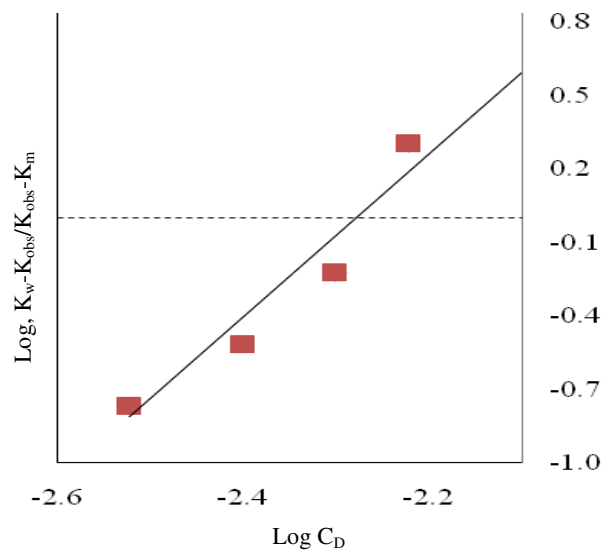

Figure 9. Index of co-operativity (n) for the oxidation of methyl red by $\mathrm{V}(\mathrm{V})$ in presence of SDS

\section{Reference}

1 Dwars T, Pactzold B and Oehme G, Angew Chem Int Edn., 2005, 44(44), 7174-7199; DOI:10.1002/anie.200501365

2 Seo S H, Chang J Y and Tew G N, Angew Chem Int Edn., 2006, 45(45), 7526-7530; DOI:10.1002/anie.200600688

3 Ryu J H, Hong D J and Lee M, Chem Commun., 2008, 1043-1054; DOI:10.1039/B713737K

4 Islam M, Saha B and Das A K, J Mol Catal: A Chem., 2005, 236(1-2), 260-266; DOI:10.1016/j.molcata.2005.04.019

5 Bayer R, Islam M, Saha B and Das A K, Carbohyd Res., 2005, 340(13), 2163-2170; DOI:10.1016/j.carres.2005.07.002

6 Islam M, Saha B and Das A K, J Mol Catal: A Chem., 2007, 266(1-2), 21-30; DOI:10.1016/j.molcata.2006.10.042

7 Saha B, Sarkar S and Choudhury K M, Int J Chem Kinet., 2008, 40(5), 282-286; DOI:10.1002/kin.20314

8 Saha B, Choudhury K M and Mandal J, J Sol Chem., 2008, 37(10), 1321-1328; DOI:10.1007/s10953-008-9304-0

9 Choudhury K M, Mandal J and Saha B, J Coord Chem., 2009, 62(11), 1871-1875; DOI:10.1080/00958970802687547

10 Bruice T C, Katzhendler J and Fedor L R, J Am Chem Soc., 1968, 90(5), 1333-1348; DOI:10.1021/ja01007a040

11 Piszkiewicz D, J Am Chem Soc., 1977, 99(5), 1550-1557; DOI:10.1021/ja00447a044; 1977, 99(23), 7695-7697; DOI:10.1021/ja00465a046; 1976, 98(10), 3053-3055; DOI:10.1021/ja00426a083

12 Gopala Rao G, Rao V P and Murty B V S R, J Analyt Chem., 1955, 147, 161. 
13 Gopala Rao G and Venkateswara Rao N, Talanta, 1961, 8(7), 539-546; DOI:10.1016/0039-9140(61)80132-X

14 Waters W A and Littler J S, J Chem Soc., 1959, 3014-3019; DOI:10.1039/JR9590003014

15 Jones J R and Waters W A, J Chem Soc., 1963, 352-356; DOI:10.1039/JR9630000352

16 Shankar J and Joshi S N, Indian J Chem., 1963, 1, 289.

17 Saccubai S and Santappa M, Indian J Chem., 1970, 8, 533.

18 Sengupta K K, Chakladar J K, Pal B P and Mukherjee D C, J Chem Soc Perkin 11, 1973, 7, 926. 